\title{
Resverol (Resveratrol) - Beneficial Effect for Prevention and Treatment of Cardio-Metabolic Syndrome
}

\author{
Teodora Handjieva-Darlenska ${ }^{1,2}$, Stella Shekerdjiiska ${ }^{2 *}$ and Nikolay Georgiev ${ }^{2}$ \\ ${ }^{1}$ Medical University of Sofia, Bulgaria \\ ${ }^{2}$ Bulgarian Association for the Study of Obesity and Related Diseases, Bulgaria \\ *Corresponding author: Stella Shekerdjiiska, Bulgarian Association for the Study of Obesity and Related Diseases, Bulgaria
}

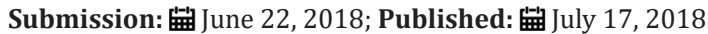

\section{Introduction}

A problem of great importance is the incidence of coronary disorders (i.e. ischemic heart disease) among transport workers deserves more attention. Our experience confirms the beneficial effect of the nutritional supplement Resverol containing Resveratrol [1].

\section{Material and Methods}

1276 transport workers, 36, 2 mean ages. All they passed through anthropometric measurements of body weight and relative body mass and through examination of their actual nutrition habits. In a part of them we measured blood pressure, cholesterolemia, triglyceridemia, glycemia and on 146 men electrocardiographic evaluations of ischemic heart disease have been carried out. As part of the nutritional prevention and management of these diseases we used nutritional supplement Resverol containing Resveratrol [2,3].

\section{Results}

Out of 1276 only $36.4 \%$ subject a normal body mass is detected, over weighted 40,3, while 23, 3-severely obese. Bearing in mind he characteristics of android obesity, leading to diabetes $(2.3 \%)$, hyperlipidemia, arterial hypertension $(25.6 \%)$ as well as early degenerative cardio-vascular alterations about 2/3 (63.6\%) there are serious anthropometric and metabolic risk factors [35]. Electrocardiographic data revealed ischemic heart disease in $65 \%$. The combination of nutritional regimen and the supplement Resverol demonstrates its favourable effect on the blood sugar levels, serum lipids and other metabolic parameters

\section{Discussion}

Resveratrol (3, 5, 4'- trihydroxy-trans-stilbene) is a stilbenoid, a type of natural phenol, and a phytoalexin produced naturally by several plants when under attack by pathogens such as bacteria or fungi [6-8]. Resveratrol is found in the skin of red grapes, some berries, peanuts and others. To drink wine in moderate amounts has long been known to have positive effects on the human body. Resveratrol is the active compound in wine and lies behind the "French Paradox", i.e. the circumstance that the incidence of coronary heart diseases are considerably fewer in southern France than in other countries- despite a high dietary intake of saturated fats. Resveratrol has also been produced by chemical synthesis or by biotechnological synthesis (bioengineered microorganisms) and is sold as a nutritional supplement derived primarily from Japanese knotweed. Resveratrol is currently a topic of numerous animal and human studies into its effects. It has been found to increase lifespan in many organisms $[9,10]$.

The mechanisms of resviratrol's apparent effects on life extension are not fully understood, but they appear to mimic several of the biochemical effects of calorie restriction. Some studies indicate the resveratrol activates Sirtuin 1 (SIRT1) and PGC- $1 \alpha$ and improve functioning of mitochondria. In mouse and rat experiments, anti-cancer, anti-inflammatory, blood sugar-lowering and others beneficial cardiovascular effects of resveratrol have been reported these results have yet to be replicated in humans.

\section{Conclusion}

There are a lot of metabolic and risk factor to cause some coronary disorders and arterial hypertension. All this can be linked to the specificities of the work activities. The inclusion of Resveratrol in the nutritional regimen improves the parameters of the glucose and lipid metabolism and emphasizes its importance in the prevention of early atherosclerosis.

\section{References}

1. Erdogan CS, Vang $O$ (2016) Challenges in analyzing the biological effects of resveratrol. Nutrients $8(6)$.

2. Ghanim H, Sia CL, Korzeniewski K, Lohano T, Abuaysheh S, et al. (2011) A resveratrol and polyphenol preparation suppresses oxidative and inflammatory stress response to a high-fat, high-carbohydrate meal. J Clin Endocrinol Metab 96(5): 1409-1414. 
3. Handjiev SV (2017) Food supplements based on compounds from the traditional nutrition in Bulgaria. Ann Nutr Metab 71(supl 2): 1194-1195.

4. La Porte C, Voduc N, Zhang G, Seguin I, Tardiff D, et al. (2010) Steadystate pharmacokinetics and tolerability of trans-resveratrol $2000 \mathrm{mg}$ twice daily with food, quercetin and alcohol (ethanol) in healthy human subjects. Clin Pharmacokinet 49(7): 449-454.

5. Lu DL, Ding DJ, Yan WJ, Li RR, Dai F, et al. (2013) Influence of glucuronidation and reduction modifications of resveratrol on its biological activities. Chembiochem 14(9): 1094-1104.

6. Smoliga JM, Blanchard O (2014) Enhancing the delivery of resveratrol in humans: if low bioavailability is the problem, what is the solution? Molecules 19(11): 17154-17172.

7. Timmers S, Konings E, Bilet L, Houtkooper RH, Vande Weijer T, et al. (2011) Calorie restriction-like effects of 30 days of resveratrol supplementation on energy metabolism and metabolic profile in obese humans. Cell Metab 14: 612-622.
8. Tome-Carneiro J, Gonzalvez M, Larrosa M, Yanez-Gascon MJ, Garcia-Almagro FJ, et al. (2013) Grape resveratrol increases serum adiponectin and down regulates inflammatory genes in peripheral blood mononuclear cells: a triple-blind, placebo-controlled, one-year clinical trial in patients with stable coronary artery disease. Cardiovasc Drugs Ther 27(1): 37-48.

9. Walker J, Schueller K, Schaefer LM, Pignitter M, Esefelder L, et al. (2014) Resveratrol and its metabolites inhibit pro-inflammatory effects of lipopolysaccharides in U-937 macrophages in plasma-representative concentrations. Food Funct 5(1): 74-84.

10. Walle T (2011) Bioavailability of resveratrol. Ann NY Acad Sci 1215: 9-15.
Creative Commons Attribution 4.0 International License

For possible submissions Click Here

\section{Submit Article}

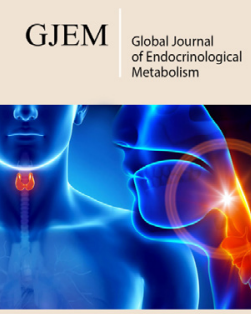

Global Journal of Endocrinological Metabolism

\section{Benefits of Publishing with us}

- High-level peer review and editorial services

- Freely accessible online immediately upon publication

- Authors retain the copyright to their work

- Licensing it under a Creative Commons license

- Visibility through different online platforms 